\title{
CrimRxiv
}

\section{Social media forensics}

applied to assessment of

post-critical incident

social reaction: The case of

the 2017 Manchester

\section{Arena terrorist attack}

Scott Jacques, Bérubé, Maxime, Tang, Thuc-Uyên, Fortin, Francis, Ozlap, Sefa, Williams, Matthew L., Burnap, Pete

Published on: Mar 03, 2022

DOI: $10.21428 / c b 6 a b 371 . a b 91321 d$

License: Creative Commons Attribution 4.0 International License (CC-BY 4.0). 
